\title{
Microarray analysis of the hyperthermophilic archaeon Pyrococcus furiosus exposed to gamma irradiation
}

\author{
Ernest Williams · Todd M. Lowe · Jeffrey Savas •
}

Jocelyne DiRuggiero

Published online: 14 December 2006

(C) Springer 2006

\section{Erratum to: Extremophiles}

DOI 10.1007/s00792-006-0002-9

In Table 1, the letters in the columns headed I-XI were not properly aligned. The corrected table is given here.

The online version of the original article can be found at http://dx.doi.org/10.1007/s00792-006-0002-9.

E. Williams · J. DiRuggiero $(\bowtie)$

Department of Cell Biology and Molecular Genetics,

University of Maryland, 3221 H.J. Patterson Hall,

College Park, MD 20742, USA

e-mail: diruggie@umd.edu

T. M. Lowe $\cdot$ J. Savas

Department of Biomolecular Engineering,

UCSC RNA Center, University of California,

Santa Cruz, 1156 High Street, Santa Cruz,

CA 95064, USA 


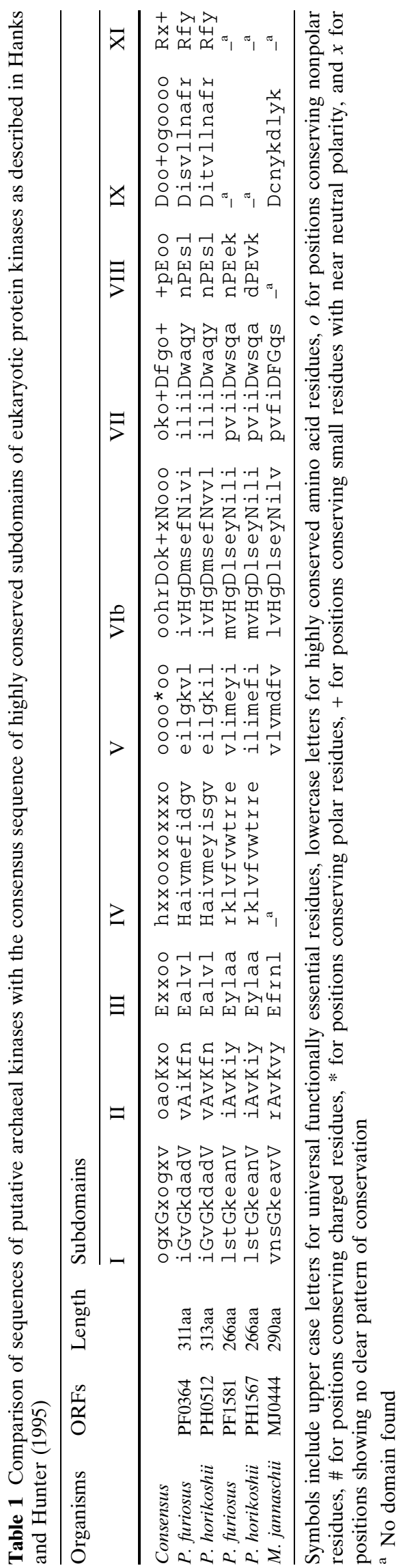

是 Springer 